\title{
Metal sensitivity in patients before and after total knee arthroplasty (TKA): comparison between ceramic surfaced oxidized zirconium and cobalt-chromium implants
}

\author{
Atsushi Kitagawa*, Takaaki Chin, Nobuhiro Tsumura and Tetsushiro Iguchi \\ *Correspondence: a_kitagawa@hwc.or.jp \\ Department of Orthopaedic Surgery, Hyogo Rehabilitation Center Hospital, Hyogo, Japan.
}

\begin{abstract}
Backgrounds: The purpose of this study was to investigate clinical relevance of preoperative screening for metal sensitivity (MS), and to assess whether there is any difference in the MS after total knee arthroplasty (TKA) between oxidized zirconium (OxZr) and cobalt-chrome (Co-Cr) implants.

Methods: A total of 48 subjects referred for TKA were enrolled the study with no history of metal allergy. After preoperative screening, we prospectively evaluated subjects, who were received either of 2 components, by comparing values of skin patch test, lymphocyte stimulation test (LST), and serum ion sampling.

$\underline{\text { Results: }}$ Preoperatively, positive rates to Co, Ni, Cr were 2.1, 6.3, 0 (\%, patch test), and were 6.3, 29.2, 16.7 (\%, lymphocyte stimulation test (LST)), respectively. Postoperatively, 1 subject (4\%) newly tested positive to Va in the Co-Cr group, and positive rates of LST to $\mathrm{Co}, \mathrm{Ni}$, and $\mathrm{Cr}$ were higher in the Co-Cr group. As the result of serum ion sampling, there was a slight increase of Co and $\mathrm{Ni}$ levels in the Co-Cr group. However, none of the subjects has developed cutaneous signs attributable to metal sensitization, and no evidence of the implant loosening was confirmed at the latest examination.

Conclusions: The finding of our study suggested that the past history alone was insufficient for identifying subjects with MS, and preoperative screening might be useful for subjects with no history of allergy. However, we could not conclude the benefit of the OxZr implant during short post-operative period.
\end{abstract}

Keywords: Metal sensitivity, total knee arthroplasty, oxidized zirconium, allergy

\section{Introduction}

Implant-related metal sensitivity has been reported mainly in case studies and metal sensitivity (MS) develops in $20-25 \%$ of patients who have undergone total knee arthroplasty (TKA) using cobalt-chrome (Co-Cr) alloy femoral components [1,2]. Metal ions can activate the immune system by inducing a delayed type IV hypersensitivity reaction, in which antigens activate T lymphocytes. Through this cascade, CD4 and CD8 cells are activated, releasing a multitude of cytokines including interferon gamma, interleukin (IL)-1, IL-6, and tumor necrosis factor (TNF) alpha, and the response of metal-specific lymphocytes has been linked to poor implant performance.

Although only a few highly susceptible $(<1 \%)$ patients exhibit symptoms such as eczema or erythema, there has been a prospective report indicating that patients with failed implants have a higher incidence of metal allergy [3]. In the general population, the mean prevalence of MS was reported be $10-17 \%[4,5]$, and the clinical relevance of preoperative screening remains controversial because there currently is little information concerning the preoperative prevalence of MS in candidates for TKA with no history of metal allergy, and the detail of the relation to postoperative allergic reaction is unknown.
In case the patient has high reactivity to a prominent implant metal such as $\mathrm{Co}$ or $\mathrm{Cr}$, an implant with an alternative bearing surface of less environmentally prevalent metals may be an option. As one of the options, oxidized zirconium, the metal surface is transformed into a ceramic layer, is increasingly being used to reduce ion release into periprosthetic tissue. It forms a thick enough ceramic layer to be more wear resistant than typical Co-Cr alloy TKA femoral components $[6,7]$. However, there is little evidence of the prognostic value of the oxidized zirconium (OxZr) component compared standard Co-Cr component for subjects with no past history of metal allergy.

The purpose of this study was to investigate clinical relevance of preoperative screening for MS by comparing values of in vivo patch test and in vitro LST. In addition, a secondary purpose of the study was to assess whether there is any significant difference in the metal sensitization after TKAs between ceramic surfaced $\mathrm{OxZr}$ and $\mathrm{Co}-\mathrm{Cr}$ femoral implants.

\section{Materials and methods}

Consecutive patients were recruited among individuals who were admitted to the authors' institution from July 2009 to May 2011. Among candidates for primary TKA, subjects who 
Kitagawa et al. Hypersensitivity 2013,

suffered from advanced osteoarthritis with no history of metal hypersensitivity were enrolled the study. After approval by the institutional review board, all participants were provided informed consent and detail of the personal history was collected by a standard questionnaire, including symptoms related to metal-induced contact dermatitis, documented by previous skin test or intolerance to metal items. Exclusion criteria were subjects with any previous history of implantations of the metal-containing devices or history of metal related contact dermatitis. In addition, subjects who suffered from rheumatoid arthritis, or those who were using corticosteroid or other immunosuppressive drugs were also excluded from the study.

A total of 48 individuals referred for TKA were enrolled the study, consisted of 6 males and 42 females with a median age of 75 years (range 64-89). MS was accessed by means of patch testing using the following haptens: $2 \%$ cobalt chloride (Co), $5 \%$ nickel sulphate (Ni), $2 \%$ chromium trichloride $(\mathrm{Cr})$ $2 \%$ aluminium chloride (Al) (Torii Pharmaceutical Co., Tokyo, Japan), 5\% vanadium trichoride (Va), 10\% titanium dioxide ( $\mathrm{Ti})$, and $5 \%$ molybdenum chloride (Mo) (Chemotechnique Diagnostics, Vellinge, Sweden). A drop of each hapten was applied to the back of the patient using chambers (Finn Chambers on Scanpor, Epitest Ltd Oy, Tuusula, Finland). Readngs were made after 48 hour, and additional reading was made after 72 hour in 34 of all cases. Skin reactions were graded according to the International Contact Dermatitis Research Group guidelines [8]. Skin reactions were classified as (1) weak positive reaction: homogeneous redness throughout the entire test area, non vesicular reaction $(+),(2)$ moderate positive reaction: homogeneous redness throughout the entire test area, oedematous or vesicular reaction (++), (3) severe positive reaction: intense homogeneous redness throughout the entire test area, bullous or ulcerative reaction $(+++)$, and (4) negative reaction: an irritant reaction, doubtful or negative reading.

For in vitro testing, blood samples were taken from each subject using a standard technique to minimize the risk of contamination for lymphocyte stimulation test (LST) to 3 haptens: $\mathrm{Co}, \mathrm{Ni}$, and $\mathrm{Cr}$. Briefly, the reactivity of lymphocytes to metals was assessed by the uptake of tritiated thymidine, and increase in $[3 \mathrm{H}]$ thymidine incorporation into metaltreated cultures was expressed as a stimulatory index (S.I.), and over $200 \%$ is considered positive. In addition, blood samples were also taken with a plastic syringe and placed in lithium heparin tubes for metal ion sampling of 3 metals, Co, $\mathrm{Ni}$, and $\mathrm{Cr}$. Serum ion levels were measured using inductively coupled plasma mass spectrometry. LST and metal ion sampling were conducted at either lab (Mitsubishi Chemical Medience Corporation, Tokyo, Japan) or at lab (Mayo Medical Laboratories, Rochester, Mn).

After preoperative screenings, all surgeries were performed using the same prosthesis design (Genesis II; Smith \& Nephew, Memphis, Tennessee) except for subject who were highly suspected of metal allergy, and the subjects were received either an $\mathrm{OxZr}$ or a Co-Cr femoral component. Oxidized zirconium (OxZr) is composed of $\mathrm{Zr}(97.5 \%)$ and niobium (2.5\%). It is proposed by submitting the alloy to heat in air to greater than $500^{\circ} \mathrm{C}$. Thermal oxidation occurs, and as the oxygen diffuses through the alloy, the immediate surface oxidizes into a $\mathrm{Zr}$ ceramic approximately $5 \mu \mathrm{m}$ thick. The alloy immediately underlying the ceramic surface has a high oxygen concentration and this gradually decreases until the alloy is just composed of the two base material. The finish material is a stable monolithic crystalline structure $[7,9]$.

The tibial component is the same for both of the femoral component options, which is modular with a polyethylene insert in a Ti-Al-Va alloy baseplate.

All surgeries were performed by the same surgeon, with the same approach and reproducible techniques for balancing flexion and extension gap and tension of collateral ligaments. The PCL was sacrificed, and the patella was not resurfaced. Both of the femoral and tibial components were cemented in all cases.

During the second 6 months after operation, MS was accessed again by means of skin patch testing, and blood samples were also taken for LST and for metal ion sampling. We performed clinical and radiographic assessments before surgery and at the latest follow-up. The knee Society rating system was used for the clinical evaluation [10]. In addition, subjects attended for clinical review for such parameters as the presence of eczematous dermatitis around operative scar, and itching, and the evidence of joint effusion. We examined follow-up radiographs (antero-posterior weight-bearing and lateral views) of all subjects. The radiolucency results were recorded according to the method recommended by the Knee Society [11]. Radiolucent lines were measured in millimeters in each designated zone for the femoral and tibial prostheses in the coronal and sagittal planes. We added the widths of radiolucent lines for Zone 1 to 7 for each of the components according to this radiographic scoring system of the Knee Society [11].

\section{Statistical analysis}

For statistical analysis, we used the paired t-test for the com-parison of pre-and post-operative metal ion sampling. These assessments were performed using software (Dr. SPSS II, developed version of SPSS 11.0; SPSS Inc., Chicago, IL). The comparison and the level of significance was set at $p<0.05$.

\section{Results}

Preoperatively, 3 of the 48 subjects showed positive patch testing to $\mathrm{Ni}$, and 1 of the 3 subjects was also positive to Co after 48 hour. The rest of the 2 subjects showed positive only to Ni. No one exhibited positive results on testing to $\mathrm{Cr}$, $\mathrm{Al}$, $\mathrm{Ti}, \mathrm{Va}$, and Mo after 48 hour. 34 of the 48 subjects, those who tested negative to all haptens, were evaluated again after 72 hour. However, no subject newly tested positive on patch 
Kitagawa et al. Hypersensitivity 2013,

Table 1. Results of preoperative screening.

\begin{tabular}{ll|ll}
\hline \multicolumn{2}{c|}{ Positive rates of patch test (\%) } & \multicolumn{2}{c}{ Results of LST } \\
\cline { 1 - 2 } Reading after 48 hour & $(\mathrm{n}=48)$ & Positive rates of LST $(\%)$ & $(\mathrm{n}=48)$ \\
\cline { 1 - 2 } To any metal & $6.3(\mathrm{n}=3)$ & To any metal & $37.5(\mathrm{n}=18)$ \\
$\mathrm{Co}$ & $2.1(\mathrm{n}=1)$ & $\mathrm{Co}$ & $6.3(\mathrm{n}=3)$ \\
$\mathrm{Ni}$ & $6.3(\mathrm{n}=3)$ & $\mathrm{Ni}$ & $29.2(\mathrm{n}=14)$ \\
$\mathrm{Cr}$ & $0(\mathrm{n}=0)$ & $\mathrm{Cr}$ & $16.7(\mathrm{n}=8)$ \\
Al, Va, Ti, Mo & $0(\mathrm{n}=0)$ & \multirow{2}{*}{$\mathrm{Al}, \mathrm{Va}, \mathrm{Ti}, \mathrm{Mo}$} & Not tested \\
\cline { 1 - 1 } Reading after 72 hour & $(\mathrm{n}=34)$ & & \\
\cline { 1 - 2 } To any metal & $0(\mathrm{n}=0)$ & & \\
\cline { 1 - 2 }
\end{tabular}

Table 2. Demographic characteristics and post-operative results.

\begin{tabular}{lll}
\hline & Co-Cr implant (n=25) & OxZr implant $(\mathbf{n}=\mathbf{2 2})$ \\
\hline Male: female & $4: 21$ & $2: 20$ \\
Mean age (year)(range) & $75.3(65$ to 89$)$ & $75.1(64$ to 85$)$ \\
$\begin{array}{l}\text { Mean follow-up period } \\
\text { (month)(range) }\end{array}$ & $24.9(13$ to 36$)$ & $24.3(13$ to 37$)$ \\
\hline \multicolumn{2}{l}{ Positive rates of patch test (\%) } & \\
\hline $\mathrm{Ni}$ & 0 & $9.0(\mathrm{n}=2)$ \\
$\mathrm{Va}$ & $4.0(\mathrm{n}=1)$ & 0 \\
Co, Cr, Al, Va, Ti, Mo & 0 & 0 \\
\hline Positive rates of LST (\%) & \\
\hline Co & $12.0(\mathrm{n}=3)$ & 0 \\
$\mathrm{Ni}$ & $24.0(\mathrm{n}=6)$ & $18.2(\mathrm{n}=4)$ \\
$\mathrm{Cr}$ & $8.0(\mathrm{n}=2)$ & $4.5(\mathrm{n}=1)$ \\
\hline
\end{tabular}

Table 3. Results of metal ion sampling (Co-Cr implant).

\begin{tabular}{llll}
\hline & \multicolumn{3}{c}{ Ion level $(\mathbf{n g} / \mathrm{mL})$} \\
\hline Metal (Mean \pm SD) & pre-operative & post-operative & p value \\
\hline $\mathrm{Co}$ & $0.24 \pm 0.05$ & $0.29 \pm 0.12$ & 0.40 \\
$\mathrm{Ni}$ & $0.10 \pm 0.03$ & $0.18 \pm 0.18$ & 0.31 \\
$\mathrm{Cr}$ & $0.30 \pm 0.19$ & $0.33 \pm 0.14$ & 0.91 \\
\hline \multicolumn{4}{c}{ Ion level (ng/mL) } \\
\hline \multicolumn{4}{c}{ Results of metal ion sampling (OxZr implant) } \\
\hline Metal (Mean \pm SD) & pre-operative & post-operative & p value \\
\hline Co & $0.24 \pm 0.06$ & $0.25 \pm 0.10$ & 0.59 \\
$\mathrm{Ni}$ & $0.11 \pm 0.03$ & $0.11 \pm 0.10$ & 0.34 \\
$\mathrm{Cr}$ & $0.25 \pm 0.17$ & $0.28 \pm 0.09$ & 0.68 \\
\hline
\end{tabular}

testing to all metal haptens. The severity of the positive skin reactions were all ( + ) weak positive reaction. As the results of LST, positive rates to Ni were highest among 3 haptens, and all subjects who were sensitive on patch testing were also positive on LST to the same hapten. However, among the subjects who had initially tested negative on patch testing to all metal haptens $(n=45), 33.3 \%$ of subjects showed positive test results on LST at least to 1 hapten. Positive rates of the preoperative screening were summarized in (Table 1).

Considering the result of the preoperative screening, one subject, who exhibited positive on both tests to Co, was strongly suspected to Co hypersensitivity. For the reason, she was excluded from the present study, and received a ceramic TKA of the different prosthesis design. 2 subjects, who tested positive on both tests to Ni were not excluded from the study, and were implanted ceramic surfaced OxZr prosthesis. The rest of subjects were tested negative on patch test to all haptens, and were selected either of 2 implants randomizedly. As the results, 22 of 47 knees were received OxZr implants, and 25 subjects were received $\mathrm{Co}-\mathrm{Cr}$ implants.

Mean follow-up periods reached 24.3 months (OxZr group), and 24.9 months (Co-Cr group), respectively at the time of the last examination, and there was no statistical difference between 2 groups. The demographic characteristics of each group were presented in (Table 2).

Postoperatively, in the OxZr group, no subject newly tested positive on patch testing to all metal haptens, except for 2 subjects who had initially positive for $\mathrm{Ni}$. In the $\mathrm{Co}-\mathrm{Cr}$ group, 1 subject (4\%) newly tested positive, (+) weak positive reaction, on patch testing to Va. However, she did not show any symptoms attributable to metal sensitization at the latest examination.

As the results of $\mathrm{LST}$, in the OxZr group, preoperative positive rates to $\mathrm{Co}, \mathrm{Ni}$, and $\mathrm{Cr}$ were $0,18.2,13.6$ (\%), respectively, and postoperative rates were $0,18.2,4.5(\%)$, respectively, including 2 subjects who tested positive to Ni preoperatively. On the other hand, in the $\mathrm{Co}-\mathrm{Cr}$ group, preoperative positive rates to $\mathrm{Co}, \mathrm{Ni}$, and $\mathrm{Cr}$ were 8.0, 36.0, $16.0(\%)$, respectively, and rates were 12.0, 24.0, 8.0 (\%) postoperatively. However, a few subjects who had initially tested positive to Ni or Cr on LST became tested negative postoperatively, and the phenomenon was confirmed in the both groups.

As the result of serum ion sampling, in the Co-Cr group, preoperative positive ion levels to $\mathrm{Co}, \mathrm{Ni}$, and $\mathrm{Cr}$ were $0.24 \pm 0.05$, $0.10 \pm 0.03,0.30 \pm 0.19(\mathrm{ng} / \mathrm{mL})$, and postoperative levels were $0.29 \pm 0.12,0.18 \pm 0.18,0.33 \pm 0.14(\mathrm{ng} / \mathrm{mL})$, respectively, which suggested a slight increase of $\mathrm{Co}$ and Ni levels during the second 6 months after operation. However, there were no statistically significant differences in levels between pre and post operative values. On the other hand, metal ion levels did not differ between pre and post operative values in the OxZr group during the same period (Table 3 ).

The knee score of the OxZr group improved from an average of 35.0 points (range 15-62 ) preoperatively to 93.4 points (range 56-100) at the latest follow-up. The score of the $\mathrm{Co}-\mathrm{Cr}$ group improved from 38.0 points (range 12 - 65) to 91.3 points (range 53-100). The average preoperative functional score of the OxZr group was 42points (range 10-75). It improved to 86.4 points (range $45-95$ ) at the latest follow-up. The score of the Co-Cr group improved from 36.2 points (range 10-70) to 84.6 points (range $40-95$ ), and there were no statistically significant differences between data of 2 groups.

To date, no knee was revised. However, one patient in the $\mathrm{Co}-\mathrm{Cr}$ group developed eczematous skin reaction and was 
Kitagawa et al. Hypersensitivity 2013,

diagnosed as superficial infection by the bacteriological test. As LST showed no increased values and the wound fully healed without complications, the reaction was not thought to be attributed to the allergic reaction. None of the subjects has developed cutaneous signs attributable to metal sensitization, and there was no episode of prolonged joint effusion, or persistent knee pain in the both groups.

As the results of radiological evaluation, there were no radiolucent lines (RLL) at the femoral interface in the the OxZr group. In contrast, RLLs of $1 \mathrm{~mm}$ were conformed in 2 knees in zone 1 with tibial components. In the Co-Cr group, there were RLLs measuring $1 \mathrm{~mm}$ in width in zone 1 of the sagittal view of femoral component in 2 patients, and RLLs of $1 \mathrm{~mm}$ were also found in 4 knees in zone 1 of the frontal view with tibial components. However, none of the subject exhibited the evidence of the implant loosening at the latest examination in the both groups.

\section{Discussion}

In the present study, we investigated the metal sensitivity prior to TKA using both skin patch testing and LST for the subjects with no history of cutaneous metal allergy, and the finding of preoperative testing suggests that past history of cutaneus allergy alone seems to be insufficient for identifying subjects with MS.

In general, individuals who should be screened prior to surgery are those reporting a history of MS, and the retrospective chart review supports the use of patch testing in patients with a clinical history of metal hypersensitivity [12]. Previous report indicated that the surgeons should undertake routine preoperative screening for MS [2]. However, currently, most agree that individuals without a reported history of metal hypersensitivity reactions need not be screened prior to implantations [13-15].

In our results, $6.3 \%$ of the subjects with no past history of metal allergy had positive results both on patch test and LST, who might potentially have increased risk of hypersensitivity to metal implants. However, our present data could not provide the evidence that implicates preexisting MS elicits metal allergy after implantation of the component containing metals to which they are reactive preoperatively because it was ethically problematic to select the conventional $\mathrm{Co}-\mathrm{Cr}$ implant for subjects with highly suspected to MS to Co or Ni. For these reasons, our study results seem to be insufficient to support the clinical relevance of preoperative screening for subjects with no history of MS as a predictive value of metal allergy.

The average prevalence of contact dermatitis was $19.5 \%$ in the general population, based on data collected on all age groups and all countries [5]. The North American Skin Patch testing group indicated the results of 4,454 patients to a wide variety of haptens. Nickel (Ni) was the most common reactant (21 percent); reactions to other substances found in orthopaedic implants such as cobalt (Co) (8 percent) and chrome (Cr) (8 percent) were on the rise [16,17]. In Japan, another report of 931 patients showed the metal to which the most patients reacted was $\mathrm{Ni}$ (27.2\%) [18], and our results also suggested Ni would be the most common sensitizer in the subject with no history of metal allergy. However, previous reports were mostly based on the results of patch test [13] and very few clinical result of LST is available, thus current modalities for metal allergy assessment (patch testing and LST) lack robust clinical validation for either their diagnostic accuracy. The patch test is a cutaneous test, and the test does not recreate the environment in which the metal resides. In addition, mixing metal chlorides used in patch testing has the potential of inducing hypersensitivity by extended dermal contact during patch testing. Therefore, although the use of LST in the assessment of MS is currently less popular than patch testing, several studies indicate that LST may have advantages over dermal patch testing for implant related hypersensitivity $[19,20]$.

Our findings of the discrepancies between 2 testing methods suggested that the LST might be more sensitive than patch test, and could be tested more safely. However, the in vitro test seems to lack adequate specificity. Therefore the LST would not be as beneficial for candidates for metal implantations as in vivo skin patch test.

Postoperatively, one subject newly tested positive for patch test and the number of subjects who tested positive for LST was increased, which could be caused by sensitization induced by metal implants. In addition, the discrepancy between values of OxZr and $\mathrm{Co}-\mathrm{Cr}$ also might be attributed to the different bearing surfaces of each component.

The occurrence of metal allergy is particularly uncommon following TKA because there is a polyethylene insert between the femoral and tibial components and no metal-on-metal contact exists, comparing metal-on-metal (MoM) total hip arthroplasty (THA), and there seems to be extremely rare subset of subjects with MS who will develop allergious reactions to implants during short period after operations. In contrast to THA [21-23], there are relatively few publications regarding metal ion exposure after TKA [24], and our investigation suggested a substantial elevation of serum metal ions in the $\mathrm{Co}-\mathrm{Cr}$ group. There is no traceable $\mathrm{Ni}$ in the $\mathrm{OxZr}$, and our data of the OxZr group implied that $\mathrm{Co}$ and $\mathrm{Cr}$ ion releases also seem to be reduced during short operative period. However, the elevation confirmed in the Co-Cr group was relatively small, comparing the literature of MoM THA, and relation of the metal ion exposure and adverse effect due to MS remains unknown.

The 5-year follow up study showed no adverse events have been observed clinically or radiologically with the same prosthesis design with OxZr [25-27]. Our results also suggested safety for subjects, including those who had the positive patch test to $\mathrm{Ni}$. The phenomenon confirmed in some subjects whose test results of LST became negative postoperatively could be due to false positive reaction or 
Kitagawa et al. Hypersensitivity 2013,

immunological tolerance induced by implants, and further studies are needed to investigate diagnostic performance of in vitro test.

A larger sample size and longer follow-up period would provide more critical information, which is a major limitation of the present study. In addition, we were not able to access the patch test reaction after 72 hour in those subjects who could not do a outpatient visit repeatedly for various reasons, which is also a limitation of the study.

\section{Conclusions}

Preoperative screening might be useful to identify MS in subjects with no history of metal related allergy. However, our results seem to be insufficient to support the clinical relevance of the screening as a predictive value of metal allergy after TKAs.

Although the present study implies that OxZr implant could be a alternative in cases of $\mathrm{Ni}$ allergy, we could not conclude the benefit of the specific implants for non allergic subjects during short post-operative period.

\section{Competing interests}

The authors declare that they have no competing interests.

Authors' contributions

\begin{tabular}{|l|c|c|c|c|}
\hline Authors' contributions & AK & TC & NT & TI \\
\hline Research concept and design & -- & $\checkmark$ & $\checkmark$ & $\checkmark$ \\
\hline Collection and/or assembly of data & $\checkmark$ & $\checkmark$ & -- & -- \\
\hline Data analysis and interpretation & $\checkmark$ & $\checkmark$ & $\checkmark$ & $\checkmark$ \\
\hline Writing the article & $\checkmark$ & -- & -- & -- \\
\hline Critical revision of the article & $\checkmark$ & $\checkmark$ & $\checkmark$ & $\checkmark$ \\
\hline Final approval of article & $\checkmark$ & $\checkmark$ & $\checkmark$ & $\checkmark$ \\
\hline Statistical analysis & $\checkmark$ & -- & $\checkmark$ & -- \\
\hline
\end{tabular}

\section{Publication history}

Editor: Francesca Larese Filon, University of Trieste, Italy.

EIC: Paul David Siegel, West Virginia University School of Pharmacy, USA.

Received: 14-Sep-2013 Revised: 21-Oct-2013

Re-Revised: 01-Nov-2013 Accepted: 17-Nov-2013

Published: 25-Nov-2013

\section{References}

1. Hallab N, Merritt $K$ and Jacobs JJ. Metal sensitivity in patients with orthopaedic implants. J Bone Joint Surg Am. 2001; 83-A:428-36. | Article I PubMed

2. Niki Y, Matsumoto $H$, Otani T, Yatabe $T$, Kondo $M$, Yoshimine $F$ and Toyama Y. Screening for symptomatic metal sensitivity: a prospective study of 92 patients undergoing total knee arthroplasty. Biomaterials. 2005; 26:1019-26. | Article | PubMed

3. Granchi D, Cenni E, Tigani D, Trisolino G, Baldini N and Giunti A. Sensitivity to implant materials in patients with total knee arthroplasties. Biomaterials. 2008; 29:1494-500. | Article | PubMed

4. Thyssen JP. The epidemiology of contact allergy. Allergen exposure and recent trends. G Ital Dermatol Venereol. 2009; 144:507-14. | Article | PubMed
5. Thyssen JP, Linneberg A, Menne T and Johansen JD. The epidemiology of contact allergy in the general population--prevalence and main findings. Contact Dermatitis. 2007; 57:287-99. | Article | PubMed

6. Bader R, Bergschmidt P, Fritsche A, Ansorge S, Thomas P and Mittelmeier $W$. [Alternative materials and solutions in total knee arthroplasty for patients with metal allergy]. Orthopade. 2008; 37:136-42. | Article | PubMed

7. Laskin RS. An oxidized Zr ceramic surfaced femoral component for total knee arthroplasty. Clin Orthop Relat Res. 2003; 191-6. | Article | PubMed

8. Drake LA, Dorner W, Goltz RW, Graham GF, Lewis CW, Pariser DM, Salasche SJ, Skouge JW, Turner ML, Lowery BJ and et al. Guidelines of care for contact dermatitis. Committee on Guidelines of Care. J Am Acad Dermatol. 1995; 32:109-13. | PubMed

9. Zeh A, Davis J, Laskin R, Klima S and Wohlrab D. Early results with the Genesis II Posterior Stabilized High Flexion knee prosthesis. A one year follow-up study. Acta Orthop Belg. 2009; 75:792-800. | Pdf | PubMed

10. Insall JN, Dorr LD, Scott RD and Scott WN. Rationale of the Knee Society clinical rating system. Clin Orthop Relat Res. 1989; 13-4. | Pdf | PubMed

11. Ewald FC. The Knee Society total knee arthroplasty roentgenographic evaluation and scoring system. Clin Orthop Relat Res. 1989; 9-12. | Article I PubMed

12. Atanaskova Mesinkovska N, Tellez A, Molina L, Honari G, Sood A, Barsoum $W$ and Taylor JS. The effect of patch testing on surgical practices and outcomes in orthopedic patients with metal implants. Arch Dermatol. 2012; 148:687-93. | Article | PubMed

13. Schalock PC, Menne T, Johansen JD, Taylor JS, Maibach HI, Liden C, Bruze $\mathrm{M}$ and Thyssen JP. Hypersensitivity reactions to metallic implants diagnostic algorithm and suggested patch test series for clinical use. Contact Dermatitis. 2012; 66:4-19. | Article | PubMed

14. Frigerio E, Pigatto PD, Guzzi G and Altomare G. Metal sensitivity in patients with orthopaedic implants: a prospective study. Contact Dermatitis. 2011; 64:273-9. | Article | PubMed

15. Granchi D, Cenni E, Giunti A and Baldini N. Metal hypersensitivity testing in patients undergoing joint replacement: a systematic review. J Bone Joint Surg Br. 2012; 94:1126-34. I Article I PubMed

16. Warshaw EM, Raju SI, Fowler JF, Jr., Maibach HI, Belsito DV, Zug KA, Rietschel RL, Taylor JS, Mathias CG, Fransway AF, DeLeo VA, Marks JG, Jr., Storrs FJ, Pratt MD and Sasseville D. Positive patch test reactions in older individuals: retrospective analysis from the North American Contact Dermatitis Group, 1994-2008. J Am Acad Dermatol. 2012; 66:229-40. | Article | PubMed

17. Zug KA, Warshaw EM, Fowler JF, Jr., Maibach HI, Belsito DL, Pratt MD, Sasseville D, Storrs FJ, Taylor JS, Mathias CG, Deleo VA, Rietschel RL and Marks J. Patch-test results of the North American Contact Dermatitis Group 2005-2006. Dermatitis. 2009; 20:149-60. | Article | PubMed

18. Nonaka H, Nakada T, lijima M and Maibach HI. Metal patch test results from 1990-2009. J Dermatol. 2011; 38:267-71. I Article I PubMed

19. Yoshihisa $Y$ and Shimizu T. Metal allergy and systemic contact dermatitis: an overview. Dermatol Res Pract. 2012; 2012:749561. | Article | PubMed Abstract | PubMed Full Text

20. Thomas P, Braathen LR, Dorig M, Aubock J, Nestle F, Werfel T and Willert HG. Increased metal allergy in patients with failed metal-on-metal hip arthroplasty and peri-implant T-lymphocytic inflammation. Allergy. 2009; 64:1157-65. | Article | PubMed

21. Vendittoli PA, Amzica T, Roy AG, Lusignan D, Girard J and Lavigne M. Metal Ion release with large-diameter metal-on-metal hip arthroplasty. J Arthroplasty. 2011; 26:282-8. I Article I PubMed

22. Shetty VD and Villar RN. Development and problems of metal-on-metal hip arthroplasty. Proc Inst Mech Eng H. 2006; 220:371-7. I Article | PubMed

23. Maurer-Ertl W, Friesenbichler J, Sadoghi P, Pechmann M, Trennheuser $M$ and Leithner A. Metal ion levels in large-diameter total hip and resurfacing hip arthroplasty--preliminary results of a prospective five year study after two years of follow-up. BMC Musculoskelet Disord. 2012; 13:56. | Article | PubMed Abstract | PubMed Full Text 
Kitagawa et al. Hypersensitivity 2013,

http://www.hoajonline.com/journals/pdf/2052-594X-1-3.pdf

24. Lutzner J, Dinnebier G, Hartmann A, Gunther KP and Kirschner S. Study rationale and protocol: prospective randomized comparison of metal ion concentrations in the patient's plasma after implantation of coated and uncoated total knee prostheses. BMC Musculoskelet Disord. 2009; 10:128. | Article | PubMed Abstract | PubMed Full Text

25. Innocenti M, Civinini R, Carulli C, Matassi F and Villano M. The 5-year results of an oxidized zirconium femoral component for TKA. Clin Orthop Relat Res. 2010; 468:1258-63. | Article | PubMed Abstract | PubMed Full Text

26. Laskin RS and Davis J. Total knee replacement using the Genesis II prosthesis: a $\mathbf{5}$-year follow up study of the first $\mathbf{1 0 0}$ consecutive cases. Knee. 2005; 12:163-7. | Article | PubMed

27. Kim YH, Park JW and Kim JS. Comparison of the Genesis II total knee replacement with oxidised zirconium and cobalt-chromium femoral components in the same patients: a prospective, double-blind, randomised controlled study. J Bone Joint Surg Br. 2012; 94:1221-7. | Article I PubMed

\section{Citation:}

Kitagawa $\mathrm{A}$, Chin $\mathrm{T}$, Tsumura $\mathrm{N}$ and Iguchi $\mathrm{T}$. Metal sensitivity in patients before and after total knee arthroplasty (TKA): comparison between ceramic surfaced oxidized zirconium and cobaltchromium implants. Hypersensitivity. 2013; 1:3. http://dx.doi.org/10.7243/2052-594X-1-3 